\title{
When Reporting on Older Patients with Cancer, Frailty Information is Needed
}

\author{
Riccardo A. Audisio, MD, FRCS $^{1}$ and Barbara van Leeuwen, PhD $^{2}$ \\ ${ }^{1}$ University of Liverpool, St Helens Teaching Hospital, St Helens, UK; ${ }^{2}$ University Medical Center Groningen, Groningen, \\ The Netherlands
}

Any effort to bring new light on the management of older patients with cancer should be welcomed and considered with interest. A large amount of evidence has now been gathered, proving significant delays in cancer detection, under-staging, and substandard treatment of this age subgroup, resulting in inferior survival. We have no standard of care and no evidence-based guidelines available for this age group because it has regularly been excluded from clinical trials: our knowledge on cancer management simply has never been validated in the older subsetting.

One note of concern rests on the fact that world-renowned centers of excellence omit data on frailty, hence failing to identify which patients have been involved in their studies. ${ }^{1-3}$ Several editorial notes also lack the same information. Reports from these researchers only include age and ASA, with no reference to comorbidities, frailty, or performance status. ${ }^{4-6}$ Consequently, these series most frequently present highly biased findings retrieved from super-selected cohorts: it is only the superfit onco-geriatric patient that reaches surgical theater. This implies that all considerations and conclusions cannot be applied to the overall geriatric population.

It would be totally unacceptable to present series without clearly stating patients' stage. The TNM staging system is fundamental in drafting treatment plans, comparing series, testing new drugs, drafting guideline, consenting patients, etc.

In a very similar way, we are no longer justified to present series of older patients without frailty data. Anagraphic age

President-Elect-SIOG, International Society Geriatric Oncology.

(C) The Author(s) 2010. This article is published with open access at Springerlink.com

Published Online: 22 September 2010

R. A. Audisio, MD, FRCS

e-mail: raudisio@doctors.org.uk is not sufficient to characterize these patients; after a decade of discussion with geriatricians, it is now clear that Comprehensive Geriatric Assessment is the most accurate instrument. Unfortunately, this is not adequate for our busy clinical practice because it requires several hours per patient. For this reason, quicker tools have been tested and validated. $^{7-9}$ These tools are capable of identifying those frail individuals who should be referred to special geriatric care before surgical management.

A modern approach should take advantage of the few available days/weeks before elective cancer surgery is planned to correct anemia, dehydration, malnourishment, and depression; optimizing the patient's conditions, as highlighted by frailty assessment tools, will eventually reduce the occurrence of operative complications. The use of neoadjuvant chemoradiation for several malignancies offers an excellent window of opportunity to this purpose.

Interestingly, present research is moving one step forward and the already available tools are being tested against quicker ones, only taking 3-5 min to administer, hence being informative and appropriate to use in our busy routine. ${ }^{10}$

We entirely agree with the authors statement that the "involvement of physicians and affiliated caregivers equipped to evaluate and apply multidisciplinary treatment programs tailored to preexisting comorbidities rather than age per se may hold the best promise for improved prognosis in this challenging clinical circumstance." ${ }^{6} \mathrm{We}$ need to bring this into clinical practice as well as scientific reporting. The lack of frailty data makes the conclusions meaningless.

OPEN ACCESS This article is distributed under the terms of the Creative Commons Attribution Noncommercial License which permits any noncommercial use, distribution, and reproduction in any medium, provided the original author(s) and source are credited. 


\section{REFERENCES}

1. Lahat G, Dhuka AR, Lahat $\mathrm{S}$, et al. Complete soft tissue sarcoma resection is a viable treatment option for select elderly patients. Ann Surg Oncol. 2009;16(9):2579-86.

2. Pultrum BB, Bosch DJ, Nijsten MW, et al. Extended esophagectomy in elderly patients with esophageal cancer: minor effect of age alone in determining the postoperative course and survival. Ann Surg Oncol. 2010;17(6):1572-80.

3. Laki F, Kirova YM, Savignoni A, et al. Management of operable invasive breast cancer in women over the age of 70: long-term results of a large-scale single-institution experience. Ann Surg Oncol. 2010;17(6):1530-8.

4. Orringer MB. Age does not preclude an esophagectomy...If only it were that simple. Ann Surg Oncol. 2010;17(6):1487-9.

5. Diehl K, Newman LA. When is age more than just a number? Ann Surg Oncol. 2010;17(6):1485-6.

6. Lev D, Pollock RE. Managing elderly soft tissue sarcoma patients: should age drive treatment? Ann Surg Oncol. 2010;16(9): 2579-86.
7. Pope D, Ramesh H, Gennari R, et al. Pre-operative assessment of cancer in the elderly (PACE): a comprehensive assessment of underlying characteristics of elderly cancer patients prior to elective surgery. Surg Oncol. 2006;15(4):189-97.

8. PACE participants, Audisio RA, Pope D, Ramesh HS, et al. Shall we operate? Preoperative assessment in elderly cancer patients (PACE) can help - a SIOG surgical task force prospective study. Crit Rev Oncol Hematol. 2008;65(2):156-63.

9. Kristjansson SR, Nesbakken A, Jordhøy MS, et al. Comprehensive geriatric assessment can predict complications in elderly patients after elective surgery for colorectal cancer: a prospective observational cohort study. Crit Rev Oncol Hematol. 2010 (in press).

10. Hempenius L, Van Leeuwen BL, Spiliotis JD, et al. PREOP: an international study of elderly surgical oncology patients to optimize preoperative assessment. Crit Rev Oncol Hematol. 2009;72(Suppl 1):PS48. 